\title{
Circulating nucleic acids in plasma and serum: diagnosis and prognosis in cancer
}

\author{
Peter Brian Gahan
}

Received: 2 April 2010 /Accepted: 13 May 2010 / Published online: 9 June 2010

(C) European Association for Predictive, Preventive and Personalised Medicine 2010

\begin{abstract}
The presence of DNA and RNA circulating in human plasma and serum is described. The known sources of the DNA/RNA in blood, the ability of these nucleic acids to enter other cells and to express in the recipient cells are considered along with their relationship to metastases. The possible role(s) of the DNA/RNA in personalized clinical diagnosis, monitoring of treatment and prognosis in oncology are discussed.
\end{abstract}

Keywords Circulating DNA/RNA · Plasma/serum . Cancer $\cdot$ Diagnosis $\cdot$ Nucleic acid uptake/expression .

Personalized medicine

\section{Introduction}

Although DNA was first demonstrated in human blood in 1948 [1] with blood from healthy donors, pregnant women and clinical patients, the information was not exploited until much later. This information disappeared from view during the major research effort of that period to understanding the chemical nature of the gene, and in particular, the structure of DNA that was still to be determined [2,3] as was its identification as the gene [4]. Much later, high DNA levels were demonstrated in the blood of patients with systemic lupus erythematosus $[5,6]$ with similar observations following for a range of illnesses [7-10] as well as in cancer patients [10]. Differences were demonstrable between those cancer patients with primary tumors only and those with metastases [11].

P. B. Gahan $(\bowtie)$

Anatomy \& Human Sciences, King's College London,

London Bridge,

London SE1 1UL, UK

e-mail: pgahan@aol.com

e-mail: peter.gahan@kcl.ac.uk
Extraction and purification of the DNA from cancer patients subsequently showed it to be tumor cell derived [12].

This review will consider some aspects of the biology of DNA/RNA found in blood, but the main focus will be on the possible role(s) of circulating nucleic acids in plasma and serum (CNAPS) in personalized cancer diagnosis, monitoring of treatment and prognosis.

\section{The source of CNAPS}

Both DNA and RNA are present in CNAPS with $1.8-35 \mathrm{ng}$ DNA ml ${ }^{-1}$ serum and $2.5 \mathrm{ng} \mathrm{RNA} \mathrm{ml}{ }^{-1}$ serum being found in healthy individuals by various analytical methods [1315]. Such nucleic acids are derived from a variety of sources in the case of those found in plasma and serum and on entering recipient cells they can modify the biology of those cells [16]. The sources for such nucleic acids in plasma and serum include (a) breakdown of blood cells; (b) bacteria and viruses, (c) leukocyte surface DNA, (d) cell and tissue necrosis, (e) apoptotic release of nucleosomes, (f) cellular release of exosomes, $(\mathrm{g})$ transposons and retrotransposons and (h) spontaneous release of a newly synthesized DNA/RNA-lipoprotein complex from living cells-"the virtosome" $[16,17]$. Of these sources, nucleosomes and virtosomes would appear to form major components of CNAPS $[16,18]$.

\section{Methodology (summarized in Fig. 1)}

Blood samples

The quality and quantity of the nucleic acids extractable from blood may depend upon the way in which the blood 


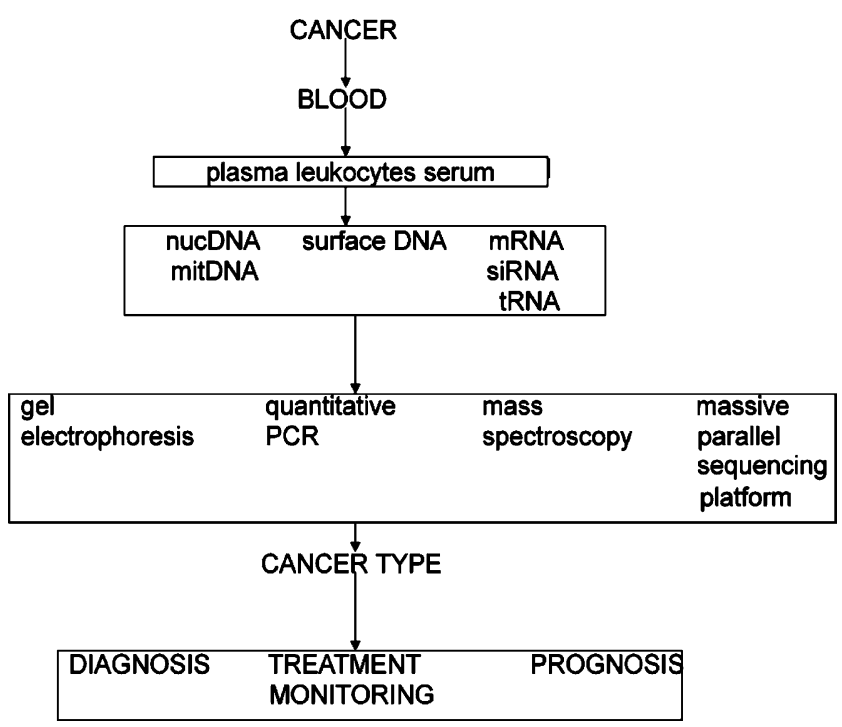

Fig. 1 Illustration of the steps between obtaining a patient blood sample and relating the isolated nucleic acids from plasma/serum and leukocyte surfaces to a particular disorder so as to allow early diagnosis, monitoring of treatment and prognosis for the patient. Some examples of the analytical processes of the isolated nucleic acid fragments are indicated

sample is handled after withdrawal from the patient given the presence of nucleases in blood. Nucleic acids can be extracted from whole blood, plasma and serum. Either the blood can be held for various periods of time $[19,20]$ or the serum/plasma are removed immediately from whole blood and stored [21] or the nucleic acids are removed and stored for further study. Cellular debris is removed by centrifugation either once or more so as to remove any cellular DNA/ RNA [22, 23]. Filtering has been used, but nucleic acids can stick to the filter and so be lost from the material to be analyzed. Furthermore, both centrifuging and filtering can result in the removal of cells with surface DNA that have been shown to be important in some diagnostic situations [24]. Hence, both centrifugation and filtration could result in a loss of nucleic acids and, to date, a standardized method handling blood samples for all situations remains to be evolved (Fig. 1).

Nucleic acid extraction from blood samples

Fleischhacker et al. [25] have compared the efficacy of DNA extraction by testing three DNA isolation kits in two different laboratories, in parallel. DNA isolation used spin columns from diverse commercial suppliers-Qiamp DNA Blood Midi Kit from Qiagen GmbH, Hilden, Germany (Q), the NucleoSpin Kit from Macherey-Nagel, Hannover, Germany (MN) and the MagNA Pure isolation system from Roche Diagnostics, Mannheim, Germany (RD). Correlations of plasma nucleosomes and cell-free DNA measured by real-time PCR were comparable between the two laboratories. Large differences in the amounts of cell-free DNA were observed between the various isolation methods, the RD isolation system giving the highest DNA yield followed by the MN and Q systems. Most comparable results with nucleosome ELISA were achieved using the Roche system [25]. Interestingly, a comparison of seven isolation methods for DNA from $2 \mathrm{ml}$ serum from colorectal cancer patients by Fong et al. [26] showed the QIAamp DNA Blood Mini Kit with carrier RNA to be the best method with the DNA fragments being of the order of $500 \mathrm{bp}+$. This highlights the difficulties in finding the most suitable method for the extraction of all DNA fragment sizes.

A recent development of the QIAamp circulating nucleic acid kit working with larger volumes of either plasma or serum may offer a more complete extraction kit [27].

A new development involving the rapid isolation and detection of CNAPS isolated directly from whole blood may offer a way of overcoming a number of the problems involved in handling fresh blood samples [28]. A microarray dielectrophoretic system can both detect and isolate high molecular weight DNA directly from whole blood with levels of $<260 \mathrm{ng} \mathrm{ml}^{-1}$ DNA being detectable. The method can also be applied to the isolation of nanoparticles at $<9.5 \times 10^{9}$ particles $\mathrm{ml}^{-1}$ [28].

Thus, although there are a number of commercial nucleic acid isolations kits available, a greater amount and broader range of fragment sizes appear to be isolated by either salting out or phenol chloroform extraction or PAGE [29]. Nevertheless, at present, there is no strict consensus as to which one method for the removal of CNAPS from blood samples for analysis is valid for all nucleic acid assays and the literature contains a wide variation of methodology.

Analytical methodology

Due to the relatively low levels of both DNA and RNA circulating in plasma and serum, the methodology exploited for diagnostic purposes is to isolate the nucleic acid and to use either digital PCR [30] or quantitative RT-PCR [31] or quantitative fluorescent PCR $[32,33]$ to increase the total amount available for further analysis. More specific analyses include the use of methylation specific PCR for the methylation of e.g. promotors [34-36]. Nevertheless, within in each PCR method there is room for possible variation [37]. The fast, low-cost Recombinase Polymerase Amplification methodology offered by TwistDx Ltd (www. twistdx.co.uk) may offer a rapid and portable system that can be used with CNAPS though this has yet to be exploited. MALDI-TOF Mass Spectrometry offers an additional way to provide quantitative, specific and sensitive analysis of circulating RNA and DNA [38] as well as rapid DNA mapping by fluorescent single molecule detection [39]. 
Both high throughput parallel sequencing platforms capable of reading 25 million bases of genetic code in $4 \mathrm{~h}$ [40] and SOLiD technology for sequencing both whole genomes and transcriptomes have also been recently developed. THE SOLiD system can deliver up to $60 \mathrm{~GB}$ of mappable sequences and provide more than 400 million sequence tags per instrument run [41]. These latter analytical approaches handling large numbers of nucleic acid fragments in very short times have permitted the introduction of the analysis of CNAPS for specific cancer associated mutations, gene methylation and the loss of heterozygosity as well as extending the use of mRNAs and including microRNAs. The exploitation of these approaches will be discussed at relevant points in this review.

\section{Circulating nucleic acids and oncology}

The first proposed uses of circulating DNA were (a) as an early marker for cancer through an increased total amount circulating DNA and (b) in monitoring treatment when DNA levels would return to normal upon treatment. Unfortunately, there was no specific correlation between the DNA fragments involved and a particular type of cancer. There have been varying levels of success with this approach.

Nucleosomes are one of the forms of DNA released into the blood stream and the role of nucleosomes in the detection of cancer has been reviewed [31]. However, in general, they are less suitable for cancer diagnosis due to elevated levels of nucleosomes in patients with benign diseases. One possible instance when nucleosomes levels correlate with tumor stage and the presence of metastases is in gastrointestinal cancers. However, they do not do so generally in other tumor types. Nevertheless, circulating nucleosomes can be used to monitor cytotoxic therapy when strongly decreasing levels are mainly found in patients with disease remission whereas constantly high or increasing values can be associated with progressive disease during chemo- and radiotherapy. Therapy outcome can be indicated by nucleosomal levels during the first week of chemo- and radiotherapy in patients with lung, pancreatic, and colorectal cancer as well as hematological malignancies. Thus, nucleosomes may have a strong role to play in therapy [31].

Similarly, the quantification of ALU repeats in the serum of breast, colorectal and periampullary cancer patients showed significantly higher values in sera of patients with cancer as opposed to those from healthy controls [42].

Recently, microRNAs have been examined in plasma and serum for use in fetal diagnosis [43, 44] and myocardial infarct assessment [45] as well as a range of cancers [46]. This approach is at an early stage of development, but shows promising signs of yielding useful marker molecules.

The cancers to be considered below will be confined to lung, colorectal, breast, ovary, prostate, glioma and nasopharyngeal and human papilloma viral carcinomas. Other cancers such as liver, kidney, head-and-neck have been less well studied for their inclusion [47-50].

\section{Lung cancer}

The technology for circulating DNA was considered insufficiently well established for its use in the diagnosis of lung cancer, Xue et al. [51] and Schmidt et al. [52] finding no significant differences between lung cancer patients and patients with a benign lung disease. Sozzi et al. [53] using real-time PCR amplification of the human telomerase reverse transcriptase gene (hTERT) in non-small cell lung cancer (NSCLC) patients versus age-, sex- and smoking-matched controls reported almost eight times the value detected in the controls $\left(24.3\right.$ v $\left.3.1 \mathrm{ngml}^{-1}\right)$. They suggested that the plasma DNA was a strong risk factor for lung cancer.

Tamkovich et al. [24] also found the average circulating DNA concentration in plasma to be similar in healthy donors and lung cancer patients. In the latter case, however, measurement of the concentration of cell-surface-bound circulating DNA showed that values for lung cancer patients were significantly lower than those of healthy donors $(P<0.0001)$ and correlated with a poor prognosis of tumor disease. Thus, individuals with poor prognosis of tumor disease could be detected with $94 \%$ sensitivity and $50 \%$ specificity. Furthermore, similar results were found for NSCLC patients [54] with the ratio of $\beta$-actin gene to LINE 1 fragments in the cell surface DNA being elevated in NSCLC patients. In addition, Wang et al. [55] identified seven biomarkers from sputum analysis that might be used for early lung cancer detection namely, loss of heterozygosity of D9S286, D9S942, GATA49D12 and D13S170, micro-satelite instability of D9S942 and methylation of p16INK4a RARß.

The role in prognosis for CNAPS, in the case of NSCLC has been exploited by Kimura et al. [56]. Cases of NSCLC carrying the somatic mutation of epidermal growth factor receptor (EGFR) were shown to be hyper-responsive to the EGFR tyrosine kinase inhibitor, gefitinib (IRESSA). Prior to commencing treatment, serum DNA from patients was subjected to Scorpion Amplified Refractory Mutation System technology to detect EGFR mutations.

The EGFR mutations were seen more frequently in patients with a partial response than in those with either stable or progressive disease $(P=0.046)$. The median progression-free survival was significantly longer in patients with EGFR mutations than in patients without EGFR mutations (200 versus 46 days; $P=0.005$ ). The 
median survival was 611 days in patients with EGFR mutations as opposed to 232 days in patients without EGFR mutations $(P>0.05)$. Thus, patients with EGFR mutations could be more successfully treated with gefitinib and hence the analysis of CNAPS could aid in the selection of NSCLC patients more readily receptive to this treatment. More recently, the authors have shown that the success rate of mutation detection of serum/plasma DNA can be increased by about $70 \%$ if whole genome nucleosomes together with other biomarkers present in serum such as progastrin-releasing enzyme, neuron-specific enolase, cytokeratin-19 fragments and carcinoembryonic antigen can be useful in predicting the efficacy of the therapy response [57]. Very preliminary studies on circulating methylated $A P C$ and RAFFSIA gene sequences by duplex real-time methylation-specific PCR were used to follow-up NSCLC patients after operation. Although the levels of $A P C$ and AFFSIA taken prior to operating could not be used for prognostic purposes, those values taken shortly after operating predicted non-reappearance in patients reexamined after 6 months [58].

\section{Colorectal cancer}

Schwarzenbach et al. [59] showed that patients with colorectal cancer had a wide range of DNA concentrations in their blood (22 to $3,922 \mathrm{ngml}^{-1}$ DNA) as compared to the average concentration of cell-free DNA in the serum of healthy donors $(5-16 \mathrm{ng} / \mathrm{ml})$ which appears to rule out the use of DNA levels for the early detection of colorectal cancers.

$\mathrm{K}$-ras mutations were exploited in the early analyses though KRAS2 was found to be present in plasma and serum of only $33 \%$ of colorectal cancer patients and absent from a number of other patients $[60,61]$. However, Ward et al. [62] found that mutant $K$-ras present in that such patients could represent an indication of adverse prognosis as confirmed by Frattini et al. [63]. Following patients postsurgery, the circulating DNA level was 25 times that of normal individuals prior to surgery while post-surgery, there was a decrease in DNA levels except in patients who subsequently developed recurrences or metastases when the DNA levels rose. A suggestion to improve the identification of tumor related DNA in blood was to take blood directly from the mesenteric/portal veins into which the CNAPS flowed instead of from the peripheral veins [64]. The markers employed included 11 micro-satellite fragments corresponding to regions on six chromosomes frequent for loss of heterozygosity in CRC the presence of hypermethylated DNA for tumor suppressor genes MGMT; p16; RAR- 32 ; RASSFIA and APC. Circulating DNA related to loss of heterozygosity and methylation was more frequently detected in blood from the mesenteric/ portal veins than from the peripheral veins [64].
It would appear that circulating nucleosomes are not reliable markers for colorectal cancer detection since they are elevated also in the presence of both cancer and benign diseases [65]. However, they may be used in monitoring treatment with decreasing levels being found in patients under remission. Increasing amounts of nucleosomes are found with progressive disease under chemo- and radiotherapy [65].

In considering nucleosomes for diagnostic purposes, Deligezer et al. [66] have recently proposed that the ratio of histone $\mathrm{H} 3$ lysine (9H3K9me3) to histone $\mathrm{H} 4$ lysine 9 (H4K20me3) in circulating nucleosomes might act as a potential diagnostic biomarker for colorectal cancer. Preliminary experiments have used trimethylation of $\mathrm{H} 3 \mathrm{~K} 9 \mathrm{me} 3$ and H4K20me3, two modifications involved in heterochromatin formation, at the peri-centric heterochromatin of circulating nucleosomes in blood plasma of the healthy individuals, patients with colorectal cancer and multiple myeloma. H3K9me3 was decreased in colorectal cancer and increased in multiple myeloma while $\mathrm{H} 4 \mathrm{~K} 20 \mathrm{me} 3$ levels were similar in all study groups. Therefore, the $\mathrm{H} 3 \mathrm{~K} 9 \mathrm{me} 3 / \mathrm{H} 4 \mathrm{~K} 20 \mathrm{me} 3$ ratio could be used to normalize H3K9me3 concentrations. This showed the ratio to be median 0.8 for colorectal patients as against median 3.0 for healthy individuals and median 4.7 for multiple myeloma patients [66].

An alternative diagnostic approach, using microRNAs (miRNAs), for colorectal cancer was developed by Schetter et al. [67] and $\mathrm{Ng}$ et al. [68]. In the latter case, of a panel of 95 microRNAs, 5 were upregulated in both plasma and serum from 25 colorectal cancer patients versus 20 healthy individuals. miR-17-3P and miR-92 were significantly elevated in the cancer patients. Plasma levels of these markers were significantly reduced after surgery in ten of the cancer patients. In addition miR-92 could be used to differentiate between colorectal and gastric cancer and irritable bowel disease patients.

\section{Breast cancer}

DNA levels appear to be greater in plasma from breast cancer patients than from normal plasma donors. Zhong et al. [69] isolated DNA from the plasma from breast cancer patients, those with benign breast lesions and healthy women. The DNA was quantified by real-time PCR for the glyceraldehyde-3-phosphate dehydrogenase gene to show 2,285, 1,368 and 1,489 genome equivalents $\mathrm{ml}^{-1}$. Thus, there were significantly greater DNA levels for breast cancer than for the controls. Furthermore, the DNA levels were high in patients with lymph node involvement and distant metastasis. Thus, these findings could have use in both diagnosis and prognosis.

Unlike in the nucleosomal studies for colorectal cancer, current investigations by Stoetzer et al. [70] found no 
absolute changes in nucleosomal levels in patients with breast cancer receiving pre-operation neoadjuvant therapy taken before commencing the first and second cycle and at the end of chemotherapy.

Nevertheless, the applicability of cyclin D2 and RAR $\beta 2$ methylated markers for the development of a breast tumor, screening assay showed mixed results [71]. Forty two per cent of the patients with primary diagnosis of breast fibroadenoma showed an aberrant methylation of at least one of the tested genes in the circulating DNA though 33\% of patients with breast lesions not diagnosed as fibroadenoma also displayed methylation.

In contrast, the findings of Divella et al. [72] showed that the level of the human hTERT gene in the plasma was significantly different for breast cancer when compared to fibroadenoma patients and healthy controls. $(p<0.01)$, showing a sensitivity of $50 \%$ and a specificity of $90 \%$ in the ability to detect malignancy. The circulating hTERT DNA was significantly different between the estrogen receptor $(\mathrm{ER})^{+} /$progesterone receptor $(\mathrm{PgR})^{+}$and the $\mathrm{ER}^{-} /$ $\mathrm{PgR}^{-}$patients $(p+0.03)$. In addition, higher hTERT levels were associated with higher human epidermal growth factor receptor-2/neu expression. Given that $h T E R T$ was significantly inversely correlated with the carbohydrate antigen (CA) 15.3 serum level $(P+0.001)$, circulating hTERT DNA appears to have a better diagnostic value than CA 15.3 in early breast cancer disease [72].

Interestingly, Contreros-Galindo et al. [73] have shown evidence for high amounts of RNA from human endogenous retrovirus K (HML-2) elements in the plasma from both breast cancer and lymphoma patients as measured by either reverse transcriptase PCR or nucleic acid base sequence amplification. A drop in RNA levels occurs on successfully treating the cancer.

\section{Ovarian cancer}

Kamat et al. [74] found that ovarian cancer patients had a median DNA level of $10,113 \mathrm{GE} \mathrm{ml}^{-1}$, compared with patients with benign ovarian neoplasms (median, 2,365 GE $\mathrm{ml}^{-1}$; $P<.0001$ ) and controls (median, 1,912 $\mathrm{GE} \mathrm{ml}^{-1}, P<.0001$ ). Cell-free DNA $>22,000 \mathrm{GE} \mathrm{ml}^{-1}$ was significantly associated with decreased patient survival $(P<.001)$. In addition, preoperative cell-free DNA $>22,000 \mathrm{GE} \mathrm{ml}{ }^{-1}$ was an independent predictor $(P=.02)$ for disease-specific survival and that cell-free DNA $>22,000 \mathrm{GEml}^{-1}$ was associated with a 2.83 -fold increased risk of death $(P<.001)$.

In another approach, Wang et al. [75] indicated that a DNA integrity index in plasma of cancer patients was highly specific and sensitive for cancer detection. The test is based on the concept that DNA fragments in serum and plasma are longer than those of healthy individuals possibly due to an inefficient nuclease activity. The amount of DNA sized $400 \mathrm{bp}$ and $100 \mathrm{bp}$ was quantified in patients with ovarian and other gynecological cancer. Significantly higher proportions of long pieces were found in the cancer patients than in both healthy controls and patients with benign ovarian diseases [75]. This confirmed the high potential of the integrity index for cancer detection and prognosis [42, 47]. However, these results were not confirmed by other workers throwing doubt on the general use of the diagnostic capacity of DNA integrity index for cancer [31]. At first sight it is their degree of differentiation of the tumor types that may make this a difficult area for CNAPS use. However, the fact that each histological form has its own characteristic genetic defect may yield an opening for the involvement of CNAPS through the detection of specific DNA fragments [76].

\section{Prostate cancer}

Boddy et al. [77] found that cancer patients had a significantly higher level of plasma DNA compared with the control group, but that DNA levels in patients with a benign biopsy were significantly higher than those in patients with confirmed cancer. Using microsatellite DNA, Müller et al. [78] found that prostate cancer (PC) patients had a DNA mean value of $590 \mathrm{ng} \mathrm{ml}^{-1}\left(81-2,792 \mathrm{ng} \mathrm{ml}^{-1}\right)$ against $48 \mathrm{ng} \mathrm{ml}^{-1}\left(45-2,908 \mathrm{ng} \mathrm{ml}^{-1}\right)$ for benign prostate hyperplasia (BPH). Nevertheless, the range of DNA values in each case would appear to limit their use in diagnosis. Of the marker genes studied, loss of heterozygosity (LOH) was highest at chromosomal regions 3p24 and 8p21 in PC patients compared with $\mathrm{BPH}$ patients frequently showing LOH at $6 \mathrm{q} 21,8 \mathrm{p} 21,9 \mathrm{p} 21$ and $11 \mathrm{q} 22$. The methylation status of tumor-related genes RASSF1A, RARß2 and GSTP1 together with genomic repeat sequences LINE 1 were also assessed [79] using methylation-specific PCR. The combined classes of marker improved detection of prostate cancer even in patients with normal prostate specific antigen. A combination of both the DNA and PSA assays gave a $89 \%$ sensitivity.

Studies on the profiles of GSTP1 gene methylation in the extracellular DNA of PC patients revealed that such profiles of patients differed from those displayed by healthy donors and patients with BPH; hence, they could possibly be used in early diagnosis. All the cytosines in the GSTP1 gene promoter in the groups of healthy donors and patients with $\mathrm{BPH}$ were unmethylated. However, the $\mathrm{CpG}$ dinucleotides in GSTP1 gene promoter in all samples from PC patients were methylated [80].

Telomere transcriptase mRNA is also a useful PC marker [81]. There were mean values of $0.79 \mathrm{ng}$ in PC patients, 0.29 in BPH patients and only $0.13 \mathrm{ng}$ in healthy individuals. Using a cut-off point of $0.35 \mathrm{ng}$, sensitivity and specificity were $81 \%$ and $60 \%$, respectively, Schwart- 
zenbach et al. [82] have suggested that the relationship between circulating DNA and tumor cells (CTC) might be exploited for early diagnosis and determination of tumor stage in prostate cancer. An epithelial immunospot assay was used to detect CTCs and a PCR-based fluorescence microsatellite analysis exploiting a panel of 14 polymorphic markers was used for the detection of allelic imbalances (AI). Plasma DNA levels significantly correlated with the subgroups of localized (M0) and metastasized (M1) prostate cancer as well as the tumor stage. AI was detected in the circulating plasma DNA from $45.0 \%$ of M0 and $58.5 \%$ of M1 patients. Seventy one percent of M0 and $92.0 \%$ of M1 patients harboured 1 to 40 CTCs in their blood, correlating with the tumor stage [82].

\section{Glioma}

There have been few studies in this area. Kyle et al. [34] determined the methylation status of the promoters for $p 16 /$ INK4a, MGMT, $p 73$, and $R A R \beta 2$ within glioma tissue and plasma by methylation specific PCR. Blood was removed from the patients prior to operation. Each methylated DNA marker found in the plasma was also present in the intracranial tumor. Patients with high-grade gliomas had high levels of DNA in the plasma. Ninety percent of these primary brain tumors contained methylated gene promoters and in over $60 \%$ of the patients, the same methylated promoters present in the tumor were also present in the plasma.

A similar approach was used by Lavon et al. [36] with astrocytomas and oligodendrogliomas of various grades. The median interval between surgery and serum sampling was 1 month (range 0.5-168 months). Loss of heterozygosity $(\mathrm{LOH})$ in chromosomes $1 \mathrm{p}, 19 \mathrm{q}$, and $10 \mathrm{q}$ was assessed by PCR-based microsatellite analysis on DNA extracted from whole blood, serum, and paraffin-embedded tumor sections. The methylation status of $\mathrm{O}^{6}$-methyl guanine methyltransferase (MGMT) and phosphatase and tensin homologue promoters was studied by methylationspecific PCR. Tumor-specific DNA was found in $80.5 \%$ of astrocytic tumors and in all oligodendrogliomas whilst the rate of serum detection did not differ between low- and high-grade oligodendrogliomas. A statistically significant tumor-serum concordance was found for MGMT methylation in both astrocytic tumors $(83 \% ; P<.001)$ and oligodendroglial tumors $(72 \% ; P<.003)$ and for LOH of $10 \mathrm{q}(79 \% ; P<.002)$ and $1 \mathrm{p}(62 \% ; P<.03)$ in oligodendrogliomas. Statistically significant tumor-serum concordance was found: (a) MGMT methylation in both astrocytic tumors $(83 \% ; P<.001)$ and oligodendroglial tumors (72\%; $P<.003)$ : (b) LOH of $10 \mathrm{q}(79 \% ; P<.002)$ and $1 \mathrm{p}$ $(62 \% ; P<.03)$ in oligodendrogliomas. There was moderate sensitivity and high specificity for both low- and high-grade tumors.
Balaña et al. [83] also used this approach for monitoring treatment showing a significantly high concordance of methylation of MGMT in glioma tissue, and paired serum DNA and the potential correlation with response and time to progression. In the 16 patients treated with temozolamide plus cisplatin, no significant correlation between MGMT methylation status and response was observed, whereas in 1,3-bis(2-chloroethyl)-1-nitrosourea (BCNU)-treated patients, a significant difference was observed in favour of those with methylated MGMT. No correlation was observed for $\mathrm{p} 16, D A P \mathrm{~K}$, or RASSF1A methylation between response or time to progression.

Circulating nucleosomes in serum and cerebrospinal fluid (CSF) from patients with glioblastoma, non-acute neurological disorders, subarachnoid hemorrhage and nonruptured aneurysms were studied to determine if they could be used in both diagnosis and prognosis [84]. In the case of patients with glioblastoma treated by surgery and local chemotherapy, levels of serum and CSF nucleosomes increased moderately during the week after surgery. There were no significant differences between pre-therapeutic nucleosome levels in the various patient groups. Those patients with glioblastoma developing cerebral edema had CSF levels increased to almost 200 - fold and reaching a maximum on day 3 after surgery in contrast to patients without edema. Thus monitoring CSF levels of nucleosomes in glioblastoma patients may indicated the development of postoperative complications [84].

RNAs may also be exploited though, in this case, it is the presence of RNA-containing exosomes released into the blood from glioblastoma patients that have been assessed. They have been shown to contain mRNA mutant/variants and miRNA characteristic of gliomas. In particular, tumorspecific EGFRvIII, containing a mutation specific for glioblastoma was detected in the serum micro-vesicles of seven out of twenty five glioblastoma patients [85].

Nasopharyngeal and human papilloma viral carcinomas

Viral DNAs have been found in CNAPS with the specific DNAs of for Epstein Barr virus (EBV) in patients with nasopharyngeal carcinoma $[86,87]$ and human papilloma viral carcinoma in about half of cervical carcinoma patients and hepatitis patients [88] having been identified. Nasopharyngeal carcinoma (NPC) is distinct from other head and neck cancers by its epidemiology, histopathology, and clinical characteristics. It is geographically endemic with an incidence as high as 25 per 100,000 in South East Asia [89]. Chan et al. [private communication] screened 1,318 subjects with no NPC. EBV viral capsid antigen (VCA-Iga) was also assayed. Sixty-nine subjects had detectable EBV DNA of which 19 were still positive 2 weeks later. On clinical follow-up, three subjects were found to have NPC 
of which only one subject showed EBV VCA-Iga positivity. Thus, CNAPS EVB DNA may have a role to play in the early diagnosis of NPC. Moreover, preliminary studies on cervical cancer patients have indicated that plasma papilloma virus DNA could be a useful marker for monitoring the therapeutic response and disease progress in cervical cancer [90].

\section{Genometastasis}

In spite of the wide range of mechanisms proposed for the induction of metastases, the involvement of CNAPS in the process is not included [91]. However, it is interesting to review the data linking circulating nucleic acids to the formation of metastases. The role of CNAPS in inducing metastasis has been explored.

Early studies showed that a newly synthesized DNA/ RNA lipoprotein complex, the virtosome, was homeostatically released from both normal and cancer cells [13, 16, 92-96]. The virtosomes could enter cells and change the biology of these cells.

Thus SW 480 cell line, originating from a human colon carcinoma, containing a point mutation of the K-ras gene on both alleles, released the DNA/RNA-lipoprotein complex containing the mutated K-ras gene. Transformed foci appeared in NIH/3T3 cells that were cultured in the presence of non-purified SW 480 cell supernatant containing the virtosome complex. The presence of a mutated ras gene in the transfected foci of the $3 \mathrm{~T} 3$ cells was confirmed by hybridization after PCR and by sequencing the PCR product [96].

Similarly, on entering non-stimulated lymphocytes, the virtosomes released from mouse tumor cell lines J774 cells (leukemia) and P497 cells (glial tumor) caused the lymphocytes to synthesize DNA for cell division [13]. No such DNA synthesis occurred if the virtosomes used were obtained from non-dividing cells.

The data above of Skog et al. [85] also implicate RNA in a similar manner.

The circulating nucleic acids in serum from patients with colorectal cancer have recently been shown to be involved in tumor induction. Thus, Garcia-Olmo et al. [97] cultured NIH-3T3 cells in the presence of plasma from patients with either K-ras-mutated colorectal tumors or from healthy subjects. The plasma was either directly added to the cultures or, to avoid plasma-cell contact, membranes with $0.4 \mu \mathrm{m}$ pores were placed between the plasma and the cells so acting as a filter. Human gene transfer occurred in most cultures of NIH-3T3 cells, as shown by the presence of human K-ras sequences, p53 sequences and ß-globin encoding sequences. That the NIH-3T3 cells were oncogenically transformed after being cultured with plasma from colon cancer patients, was demonstrated by injecting the transformed NIH-3T3 cells into NOD-SCID mice that went on to develop tumors. The presence of an artificial membrane containing $4 \mu \mathrm{m}$ diameter pores placed between the NIH-3T3 cells and the plasma gave similar results showing that the transforming factor had a diameter of less than $0.4 \mu \mathrm{m}$. A TEM study of the membranes from the plasma experiments showed many structures of $<0.4 \mu \mathrm{m}$ diameter were seen to pass through the pores of membrane. This process has been termed Genometastasis [98, 99]. Serrano-Heras et al. [100] have suggested that the structures passing through the pores are DNA-carrying exosomes. However, the ability of the virtosomes released from tumor cells to enter and stimulate DNA synthesis in nonstimulated lymphocytes [13] and the presence of the mutated K-ras gene DNA released from SW480 cells into the culture medium to be present in the transformed NIH/ 3 T3 cells [96], implies that the virtosomes could also be implicated in the metastatic process.

\section{Conclusions \& outlook}

Fragments of DNA and the various forms of RNA are clearly circulating in blood and there are important early signs that they may be used as early diagnostic markers for a number of disorders. Clearly, both DNA and RNA have roles to play in personalized diagnosis and prognosis in clinical oncology.

At present, clinical trials are in progress in the USA and the UK for the use of CNAPS from maternal blood as a minimally invasive method for examination of the fetus in the first trimester e.g. for diagnosis of Down syndrome and $\mathrm{Rh}$ factors. However, as can be seen above, the use of CNAPS in personalized cancer detection is very much at the experimental stage with many exciting prospects. Few developments are at a stage where clinical trials can be held though there are hopeful signs that the use of nucleosomes to monitor cancer treatment, but not for diagnostic purposes, can be established [25, 31, 57, 65, 84]. This highlights the fact that, although many laboratories around the world are engaged upon the applications of CNAPS in personalized cancer studies and that a number of patents have been obtained for various technical processes, there are a limited number of laboratories working on any one type of cancer and so progress to clinical use is relatively slow.

Much more emphasis needs to be placed on improving the quality of the methodology for consistency in usage across laboratories before this approach can be put onto a broad basis. This applies to the storage of blood samples, the isolation of all nucleic acid fragments from the blood and the method for analyzing those fragments. The new 
methodology [40, 41] for sequencing the nucleic acid fragments in very short time periods allows for the identification of a large range of markers that may be used for any one cancer. However, time is still needed to determine how best to handle so much data generated with respect to cancer diagnosis and prognosis.

Attention is drawn to the evidence that some of the nucleic acids in plasma and serum released from primary tumors can act as messengers between cells and are implicated in the initiation metastases. This poses questions concerning the use for transfusion of blood taken from individuals who, unknowingly, have cancer.

\section{References}

1. Mendel P, Métais P. Les acides nucléiques du plasma sanguine chez l'homme. CR Acad Sci Paris. 1948;142:241-3.

2. Watson JD, Crick FH. A structure for deoxyribose nucleic acid. Nature. 1953;171:737-8.

3. Wilkins MH, Stokes AR, Wilson HR. Molecular structure of deoxypentose nucleic acids. Nature. 1953;171:738-40.

4. Sinsheimer RL. First steps toward a genetic chemistry. Science. 1957; 125:1123-8.

5. Koffler D, Agnello V, Winchester R. The occurrence of singlestranded DNA in the serum of patients with systemic lupus erythrematosus and other diseases. J Clin Invest. 1973;52:198-204.

6. Tan EM, Schur PH, Carr RI, et al. Deoxyribonucleic acid (DNA) and antibodies to DNA in the serum of patients with systemic lupus erythrematosus. J Clin Invest. 1966;45:1732-40.

7. Rainer TH, Wong LK, Lam W, et al. Prognostic use of circulating plasma nucleic acid concentrations in patients with acute stroke. Clin Chem. 2003;49:562-9.

8. Lam NY, Rainer TH, Chan LY, et al. Time course of early and late changes in plasma DNA in trauma patients. Clin Chem. 2003;49:1286-91.

9. Chiu TW, Young R, Chan LYS, et al. Plasma cell-free DNA as an indicator of severity of injury in burn patients. Clin Hem Lab Manag. 2006;44:13-7.

10. Gahan PB. Circulation nucleic acids in plasma and serum: roles in diagnosis and prognosis in diabetes and cancer. Infect Disord Drug Targets. 2008;8:100-8.

11. Leon SA, Shapiro B, Sklaroff DM, et al. Free DNA in the serum of cancer patients and the effect of therapy. Cancer Res. 1977;37:646-50.

12. Stroun M, Anker P, Maurice P, et al. Neoplastic characteristics of the DNA found in the plasma of cancer patients. Oncology. 1989;46:318-22.

13. Anker P, Stroun M, Maurice P. Spontaneous release of DNA by human blood lymphocytes as shown in an in vitro system. Cancer Res. 1975;35:2375-82.

14. Rykova EY, Bryzgunova OE, Skvortsova TE, Tamkovich TN, Senin IN, Laktionov PP, et al. Concentrations of circulating RNA from healthy donors and cancer patients. Ann NY Acad Sci. 2006;1075:328-33.

15. Holford NC, Ramoutar A, Butt AN, et al. Normalization of circulating nucleic acid results. Should we use $\beta$-actin? Ann NY Acad Sci. 2008;1137:112-8.

16. Gahan PB, Stroun M. The biology of circulating nucleic acids in plasma and serum. In: Rykova EY, Kikuchi Y, editors. Extracellular nucleic acids. In Series "Nucleic Acids and Molecular Biology" Springer Berlin; 2010, in press
17. Gahan PB, Stroun M. The virtosome - a novel cytosolic informative entity \& intercellular messenger. Cell Biochem Funct; 2010, submitted

18. Gahan PB. Circulating nucleic acids in plasma and serum: roles in diagnosis and prognosis. In: Golubnitschaja $\mathrm{O}$, editor. Predictive diagnostics and personalised treatment. Boston: Nova Science Publishers; 2009.

19. Tsui NB, Ng EK, Lo YMD. Stability of endogenous and added RNA in blood specimens, serum, and plasma. Clin Chem. 2002;48:1647-53.

20. Holford NC, Sandhu HS, Thakkar H, et al. Stability of $\beta$-Actin mRNA in plasma. Ann NY Acad Sci. 2008;1137:108-11.

21. Board RE, Williams VS, Knight L, et al. Isolation and extraction of circulating tumor DNA from patients with small cell lung cancer. Ann NY Acad Sci. 2008;1137:98-107.

22. Page K, Powles T, Slade MJ, et al. The importance of careful blood processing in isolation of cell free DNA. Ann NY Acad Sci. 2006;1075:313.

23. Dovc-Drnovsek T, Emersic B, Rozman P. Optimisation of purification of human cell-free mRNA from plasma. Ann NY Acad Sci. 2008;1137:125-9.

24. Tamkovich SN, Litvjakov NV, Bryzgunova OE, et al. Cellsurface-bound circulating DNA as a prognostic factor in lung cancer. Ann NY Acad Sci. 2008;1137:214-7.

25. Fleischhacker M, Schmidt B, Weickmann S et al. Comparison of nucleosomes and quantitative PCR using diverse DNA isolation methods. In "Circulating Nucleic Acids in Plasma and Serum". Ed. PB Gahan. Berlin: Springer; 2010, in press

26. Fong SL, Zhang JT, Lim CK. Comparison of 7 methods for extracting cell-free DNA from serum samples of colorectal cancer patients. Clin Chem. 2009;55:587-9.

27. Horlitz M, Hartinger T, Graf S, et al. Yields of viral and circulating cell-free nucleic acids using the QIAamp ${ }^{\circledR}$ circulating nucleic acid kit. In: Gahan PB, editor. Circulating nucleic acids in plasma and serum. Berlin: Springer; 2010. in press.

28. Krishnann R, Heller MJ. Rapid isolation and detection of cell free circulating DNA and other disease biomarkers directly from whole blood. In: Gahan PB, editor. Circulating nucleic acids in plasma and serum. Berlin: Springer; 2010. in press.

29. Van der Vaart M, Pretorius PJ. A method for characterization of total circulating DNA. Ann NY Acad Sci. 2008;1137:92-7.

30. Lo YMD, Lun FMF, Chan KCA, et al. Digital PCR for the molecular detection of fetal chromosomal aneuploidy. Proc Natl Acad Sci USA. 2007;104:13116-21.

31. Holdenrieder S, Burges A, Reich O, et al. DNA integrity in plasma and serum of patients with malignant and benign diseases. Ann NY Acad Sci. 2008;1137:162-70.

32. Ciriglian V, Voglino G, Marongiu A, et al. Rapid prenatal diagnosis by QF-PCR: evaluation of 30,000 consecutive clinical samples and future applications. Ann NY Acad Sci. 2006;1075: 288-98.

33. Gole L, Adrianne F, Ee AM. Refining quantitative fluorescent polymerase chain reaction for prenatal detection of X chromosomal anomalies in the major Southeast Asian populations. Singapore Med J. 2008;49:1025-8.

34. Kyle D, Weaver MD, Stuart A, et al. Methylated tumor-specific DNA as a plasma biomarker in patients with glioma. Cancer Investig. 2006;24:35-40.

35. Sunami E, Shinozaki M, Higano CS, et al. Multimarker circulating DNA assay for assessing blood of prostate cancer patients. Clin Chem. 2009;55:559-67.

36. Lavon I, Refael M, Zelikovitch B, et al. Serum DNA can define tumor-specific genetic and epigenetic markers in gliomas of various grades. Neuro-Oncology. 2010;12:173-80.

37. Le Q-T, Jones CD, Yau T-K, et al. A comparison study of different PCR assays in measuring circulating plasma epstein- 
barr virus DNA levels in patients with nasopharyngeal carcinoma. Clin Cancer Res. 2005;11:5700-12.

38. Ding C, Lo YM. MALDI-TOF mass spectrometry for quantitative, specific, and sensitive analysis of DNA and RNA. Ann NY Acad Sci. 2006;1075:282-7.

39. Ming X, Phong A, Ha C, et al. Rapid DNA mapping by fluorescent single molecule detection. Nucleic Acids Res. 2007;35(3):e16. doi:10.1093/nar/gk11044.

40. Rogers YH, Ventner JC. Genomics: massively parallel sequencing. Nature. 2005;437:326-7.

41. Rossa WK, Sun CH, Akolekar R, et al. Maternal plasma DNA analysis with massively parallel sequencing by ligation for noninvasive prenatal diagnosis of trisomy 21 . Clin Chem. 2010;56:459-63.

42. Umetani N, Kim J, Hiramats S, et al. Increased integrity of free circulating DNA in sera of patients with colorectal. Clin Chem. 2006;52:1062-9.

43. Chim SSC, Shing TKF, Hung ECW. Detection and characterization of placental microRNAs in maternal plasma. Clin Chem. 2008;54:482-90.

44. Hung ECW, Chiu RWK, Lo YMD. Detection of circulating fetal nucleic acids: a review of methods and applications. J Clin Path. 2009;62:308-13.

45. Ji X, Takahashi R, Hiura Y, et al. Plasma miR-208 as a biomarker of myocardial injury. Clin Chem. 2009;55:1944-9.

46. Lodes MJ, Caraballo M, Suciu D, et al. Detection of cancer with serum microRNAs on an oligonucleotide microarray. PLoS ONE. 2009;14:e622.

47. Jiang WW, Zahurak M, Goldenberg D. Increased plasma DNA integrity index in head and neck cancer patients. Int $\mathrm{J}$ Cancer. 2007;119:2673-6.

48. Daniotti M, Vallacchi V, Rivoltini L, et al. Detection of mutated BRAFV600E variant in circulating DNA of stage III-IV melanoma patients. Int J Cancer. 2007;120:2439-44.

49. Cheung ST, Fan ST, Lee YT, et al. Albumin mRNA in plasma predicts post-transplant recurrence of patients with hepatocellular carcinoma. Transplantation. 2008;85:81-7.

50. Gang F, Guorong L, An Z, et al. Prediction of clear cell renal cell carcinoma by integrity of cell-free DNA in serum. Urology. 2010;75:262-5.

51. Xue X, Zhu YM, Woll PA. circulating DNA in lung cancer. Ann NY Acad Sci. 2006;1075:154-64.

52. Schmidt B, Weickmann S, Witt $\mathrm{C}$, et al. Integrity of cell-free plasma DNA in patients with lung cancer and nonmalignant lung disease. Ann NY Acad Sci. 2008;1137:207-13.

53. Sozzi G, Conte D, Leon ME. Quantification of free circulating DNA as a diagnostic marker in lung cancer. J Clin Oncol. 2003;21:3902-8.

54. Ponomaryova AA, Rykova EY, Cherdyntseva NV, et al. Concentration and distribution of single-copy $\beta$-actin gene and LINE-1 repetitive elements in blood of lung cancer patients. In: Gahan PB, editor. Circulating nucleic acids in plasma and serum. Berlin: Springer; 2010. in press.

55. Wang YC, Hsu HS, Chen TP, et al. Molecular diagnostic markers for lung cancer in sputum and plasma. Ann NY Acad Sci. 2006;1075:179-84.

56. Kimura H, Kasahara K, Kawaishi M, et al. Detection of epidermal growth factor receptor mutations in serum as a predictor of the response to gefitinib in patients with non-small cell lung cancer. Clin Cancer Res. 2006;13:3915-21.

57. Holdenreider S, van Pawel J, Duell T, et al. Circulating nucleosomes and oncogenic biomarkers in monitoring chemotherapy of small cell lung cancer. In: Gahan PB, editor. Circulating nucleic acids in plasma and serum. Berlin: Springer; 2010. in press.

58. Ding Q, Mu Y, Pan S, et al. Plasma DNA methylation analysis in predicting short-term recurrence of surgical patients with non- small cell lung cancer (NSCLC). In: Gahan PB, editor. Circulating nucleic acids in plasma and serum. Berlin: Springer; 2010. in press.

59. Schwarzenbach H, Stoehlmacher J, Pantel K, et al. Detection and monitoring of cell-free DNA in blood of patients with colorectal cancer. Ann NY Acad Sci. 2008;1137:190196.

60. Sorenson GD. A review of studies on the detection of mutated KRAS2 sequences as tumor markers in plasma/serum of patients with gastrointestinal cancer. Ann NY Acad Sci. 2000;906:13-6.

61. Su YH, Wang M, Brenner DE, et al. Detection of mutated K-ras in urine, plasma and serum of patients with colorectal carcinoma or adenomatous polyps. Ann NY Acad Sci. 2008;1137:197-206.

62. Ward R, Sheehan C, Norrie M, et al. Factors influencing the detection of mutant K-ras in the serum of patients with colorectal cancer. Ann NY Acad Sci. 2000;906:17-8.

63. Frattini M, Gallino G, Signoroni S, et al. Quantitative analysis of plasma DNA in colorectal cancer patients. Ann NY Acad Sci. 2006;1075:185-90.

64. Taback B, Saha S, Hoon DSB. Comparative analysis of mesenteric and peripheral blood circulating tumor DNA in colorectal cancer. Ann NY Acad Sci. 2006;1075:197-203.

65. Holdenrieder S, Nagel D, Schalhorn A. Clinical relevance of circulating nucleosomes in cancer. Ann NY Acad Sci. 2008;1137:180-9.

66. Deligezer U, Akisik EZ, Akisik EE, et al. H3K9me3/H4K20me3 ratio in circulating nucleosomes as potential biomarker for colorectal cancer. In: Gahan PB, editor. Circulating nucleic acids in plasma and serum. Berlin: Springer; 2010. in press.

67. Schetter AJ, Harris CC. Plasma microRNAs: potential biomarker for colorectal cancer? Gut. 2009;58:1318-9.

68. $\mathrm{Ng}$ EKO, Chong WWS, Jin $\mathrm{H}$, et al. Differential expression of microRNAs in plasma of patients with colorectal cancer: a potential marker for colorectal cancer screening. Gut. 2009;58:1375-81. doi:10.1136/gut.2008.167817.

69. Zhong XY, Ladewig A, Schmid S, et al. Elevated level of cellfree plasma DNA is associated with breast cancer. Arch Gynecol Obstet. 2007;276:327-31.

70. Stoetzer OJ, Fersching DMI, Holdenrieder S. Circulating nucleosomes and DNAse in breast cancer patients during neoadjuvant chemotherapy. In: Gahan PB, editor. Circulating nucleic acids in plasma and serum. Berlin: Springer; 2010. in press.

71. Rykova EY, Tsvetovskaya GA, Sergeeva GI, et al. Methylationbased analysis of circulating DNA for breast tumor screening. Ann NY Acad Sci. 2008;1137:232-5.

72. Divella R, Tommasi S, Lacalamita R, et al. Circulating hTERT DNA in Early Breast Cancer. Anticancer Res. 2009;29:2845-9.

73. Contreros-Galindo R, Kaplan MH, Leissner P, et al. Human endogenous retrovirus K (HML-2) elements in the plasma of people with lymphoma and breast cancer. J Virol. 2008;82:9329-36.

74. Kamat A, Baldwi M, Urbauer D, et al. Plasma cell-free DNA in ovarian cancer. Cancer. 2010. doi:10.1002/cncr.24997.

75. Wang BG, Huang HY, Chen YC, et al. Increased plasma DNA integrity in cancer patients. Cancer Res. 2003;63:3966-8.

76. Cho KR, Shih IM. Ovarian cancer. Annu Rev Pathol-Mech. 2009;4:287-313.

77. Boddy JL, Gal S, Malone PR, et al. Prospective study of quantitation of plasma DNA levels in the diagnosis of malignant versus benign prostate disease. Clin Cancer Res. 2005;11:1394-9.

78. Muller I, Urban K, Pantel K, et al. Comparison of genetic alterations detected in circulating microsatellite DNA in blood plasma samples of patients with prostate cancer and benign hyperplasia. Ann NY Acad Sci. 2006;1075:222-9.

79. Hoon DSB, Shinozaki M, Higano CS, et al. Circulating DNA serum biomarkers of different forms utility in evaluating prostate 
cancer patients. In: Gahan PB, editor. Circulating nucleic acids in plasma and serum. Berlin: Springer; 2010. in press.

80. Bryzgunova OE, Morozkin ES, Yarmoschuk SV, et al. Methylation-specific sequencing of GStP1 gene promoter in circulating/extracellular DNA from blood and urine of healthy donors and prostate cancer patients. Ann NY Acad Sci. 2008; 1137:222-5.

81. Dasi F, Martinez-Rodes P, March JA, et al. Real-time quantification of human telomerase reverse transcriptase mRNA in the plasma of patients with prostate cancer. Ann NY Acad Sci. 2006;1075:204-10.

82. Schwarzenbach H, Alix-Panabières C, Müller I, et al. Cell-free tumor DNA in blood plasma as a marker for circulating tumor cells in prostate cancer. Clin Cancer Res. 2009;15:1032-8.

83. Balaña C, Ramirez JL, Taron M, et al. O6-methyl-guanine-DNA methyltransferase methylation in serum and tumor DNA predicts response to 1, 3-bis(2-chloroethyl)-1-nitrosourea but not to temozolamide plus cisplatin in glioblastoma multiforme. Clin Cancer Res. 2003;9:1461-8.

84. Holdenrieder S, Spuler A, Tischinger M, et al. Presence of nucleosomes in cerebrospinal fluid of glioblastoma patientspotential for therapy monitoring. In: Gahan PB, editor. Circulating nucleic acids in plasma and serum. Berlin: Springer; 2010. in press.

85. Skog J, Würdinger T, van Rijn S, et al. Glioblastoma microvesicles transport RNA and proteins that promote tumor growth and provide diagnostic biomarkers. Nat Cell Biol. 2008;10: 1470-6.

86. Lo YM, Chan LY, Lo KW, et al. Quantitative analysis of cell-free Epstein-Barr virus DNA in plasma of patients with nasopharyngeal carcinoma. Clin Cancer Res. 1999;59:1188-91.

87. Chan ATC, Teo PML, Johnson PJ. Nasopharyngeal carcinoma. Ann Oncol. 2002;13:1007-15.

88. Yang HJ, Liu VW, Tsang PC, et al. Quantification of human papilloma virus DNA in the plasma of patients with cervical cancer. Int J Gynecol. 2004;14:93-910.

89. Niedobitek G. Epstein-Barr virus infection in the pathogenesis of nasopharyngeal carcinoma. Mol Pathol. 2000;53:248-54.
90. Yang HJ, Liu VW, Tsang PC, et al. Quantification of human papilloma virus $\mathrm{DN}$ in the plasma of patients with cervical carcinoma. Int J Gynecol Cancer. 2004;14:903-10.

91. Adams DH, Gahan PB. Stimulated and non-stimulated rat spleen cells release different DNA-Sciences Genève complexes. Differentiation. 1982;22:47-52.

92. Adams DH, Gahan PB. The DNA extruded by rat spleen cells in culture. Int J Biochem. 1983;15:547-52.

93. Stroun M, Anker P, Gahan PB, Henri J. Spontaneous release of newly synthesized DNA from frog auricles. Arch Sci (Genève). 1977;30:229-42.

94. Anker P, Lyautey J, Lefort F, Lederrey C, Stroun M. Transformation of NIH/3T3 cells and SW 480 cells displaying K-ras mutation. CR Acad Sci III. 1994;10:869-74.

95. Adams DH, Diaz N, Gahan PB. In vitro stimulation by tumor cell media of $[3 \mathrm{H}]$ thymidine incorporation by mouse spleen lymphocytes. Cell Biochem Funct. 1997;15:119-26.

96. García-Olmo DC, Domínguez C, García-Arranz M, et al. Cellfree nucleic acids circulating in the plasma of colorectal cancer patients induce the oncogenic transformation of susceptible cultured cells. Cancer Res. 2010;70:560-7.

97. García-Olmo D, García-Olmo DC, Ontañón J, et al. Tumor DNA circulating in the plasma might play a role in metastasis. The hypothesis of genometastasis. Histol Histopathol. 1999;14: 1159-64.

98. García-Olmo D, García-Olmo DC, Ontañón J, et al. Horizontal transfer of DNA and the "genometastasis hypothesis". Blood. 2000;95:724-5.

99. Garcia-Olmo DC, Ruiz-Piqueras R, Garcia-Olmo D. Circulating nucleic acids in plasma and serum (CNAPS) and its relation to stem cells and cancer metastasis: state of the issue. Histol Histopathol. 2004;19:575-83.

100. Serrano-Heras G, García-Olmo D, García-Olmo DC. Microvesicles circulating in plasma of rats contain DNA. Are these small vesicles a main source of cell-free DNA in plasma? In: Gahan PB, editor. Circulating nucleic acids in plasma and serum. Berlin: Springer; 2010. in press. 